\title{
La conciliación de lo político y lo religioso. Suárez y Hobbes sobre la potestad indirecta
}

The conciliation of the political and the religious. Suarez and Hobbes on indirect power

Miguel Saralegui

Universidad Adolfo Ibáñez Departamento de Filosofía Facultad de Artes liberales 7941169 Santiago (Chile) (miguelsaralegui@gmail.com)

Abstract: In this article, I study Suarez's defense of the Pope's indirect power and Hobbes criticism of the same. Although Suarez's view is normally regarded as moderate, here I indicate his closeness to theocracy. In addition, I show that, while Hobbes may be closer to the contemporary position, his tendency towards monocracy makes him unable to account for the possibility of a harmonic coexistence between spiritual and religious powers.

Keywords: Suarez, Hobbes, indirect power, monocracy.
Resumen: En este artículo, se estudiará la defensa de Suárez de la potestad indirecta, así como la crítica de Hobbes, tema descuidado por la bibliografía. A pesar de que se suele considerar la postura suareciana como moderada, insistiré en su similitud con la teocracia. Por otra parte, aunque se reconocerá a Hobbes como más cercano a la solución contemporánea, se recordará que su pulsión monocrática le impide dar cuenta de cómo es posible la coexistencia armónica de un poder civil y otro religioso.

Palabras clave: Suárez, Hobbes, potestad indirecta, monocracia. 


\section{LA NECESIDAD CRISTIANA DE CONCILIAR AUTORIDAD CIVIL Y RELIGIOSA}

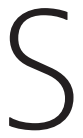

in atribuirle una novedad absoluta en la historia de las religiones, la realidad efectiva del cristianismo ha suscitado durante largos periodos un enfrentamiento, a veces violento, entre autoridad civil y religiosa. Esta conflictividad nace de la posibilidad de distinguir netamente entre esfera espiritual y material. En tanto que esta separación no la respalda toda religión, es previsible que la solución de la filosofía política, cuando se elabora en un ambiente cristiano, esté permeada por esta experiencia religiosa. Las diferentes conciliaciones propuestas no son puramente abstractas, sino que están determinadas por las eclesiologías de las diferentes variedades del cristianismo. Incluso si fuese plausible que el postcristianismo de las sociedades contemporáneas permitiera prescindir de su origen cristiano para legislar la relación entre autoridad civil y religiosa, la historia del pensamiento político no se puede permitir ni esta abstracción ni sobre todo este anacronismo. En el contexto particular de la experiencia histórica del cristianismo se debe interpretar la reflexión de la filosofía política moderna. De esta manera, la conciliación que Suárez y Hobbes establecen entre la esfera civil y la religiosa no son inteligibles, si se desatiende a su vez la particularidad del cristianismo que envuelve su producción.

Los siglos XVI y XVII son especialmente conflictivos para la historia del cristianismo. Las nuevas confesiones cristianas entienden de modo diverso la relación entre poder civil y religioso. En un contexto marcadamente intracristiano, dos de los más importantes filósofos políticos de este periodo - Francisco Suárez y Thomas Hobbes- ofrecen diferentes maneras de entender el vínculo entre esfera civil y religiosa. Abandonado el paradigma griego que considera a la política el lugar de la plenificación moral, ambos pensadores consideran que la política busca primariamente la paz. También alejados de Maquiavelo, para ambos pensadores la política no es de jure una realidad conflictiva. La guerra civil y la injerencia de una autoridad sobre otra se deben a que los actores políticos no han sido capaces de reconocer la estructura de una realidad en sí misma ordenada. 
Estudiar a Hobbes como crítico de la potestad indirecta no supone novedad alguna. El mismo filósofo inglés se querrá deshacer de esta teoría en el libro III y IV del Leviatán, a través de la crítica explícita a una de sus bestias negras intelectuales: Roberto Belarmino ${ }^{1}$. Tanto la doctrina de Belarmino de la potestad indirecta como la crítica que Hobbes le dedica han sido estudiadas recurrentemente ${ }^{2}$. Aunque más desatendido, tampoco es original examinar el concepto de la potestad indirecta en el pensamiento de Suárez ${ }^{3}$. Sin embargo, la relevancia de este trabajo se puede justificar por tres motivos. En primer lugar, los análisis de la relación entre Suárez y Hobbes se han centrado en aspectos diferentes a la teoría de la potestad indirecta y del poder político ${ }^{4}$ En segundo lugar, la crítica de Hobbes a la potestad indirecta puede interpretarse como el colofón de la larga disputa anglo-española que marca el fin del XVI y el comienzo del XVII. Esta perspectiva resulta interesante, pues Suárez y Hobbes mantienen relaciones paralelas con los monarcas de quienes fueron vasallos: ambos fueron amigos cercanos de reyes - Felipe III de España y Carlos II de Inglaterra- y publican su teoría política con una edad de más de sesenta años. En tercer lugar, hasta el final de los setenta del siglo XX, la bibliografía española sobre la filosofía política

1. T. HobBes, Discursos histórico-políticos (Gorla, Buenos Aires, 2006) 100: "impresionaba por su sabiduría: era Belarmino".

2. P. Springborg, Thomas Hobbes and Cardinal Bellarmine: Leviathan and the Ghost of the Roman Empire, "History of Political Thought" XVI (1995) 503-531; E. FABBRI, Roberto Bellarmino e Thomas Hobbes. Teologie politiche a confronto (Aracne, Roma, 2009). Sobre la teoría de Belarmino, existe una abundante bibliografía: J. CouRTENEY Murray, St. Robert Bellarmine on the Indirect Power, "Theological Studies" IX (1948) 491-535; B. Bourdin, Theological-Political Origins of the Modern State (Catholic University of America, Washington D.C., 2010); S. TuTINO, Empire of Souls. Robert Bellarmine and the Christian Commonwealth (Oxford University Press, Oxford, 2010); P. PRODI, El soberano pontífice (Akal, Madrid, 2011).

3. Fuera de los estudios eclesiásticos, J. BROWn SCOTT, The Catholic Conception of International Law (Georgetown University Press, Washington D. C., 1934). En la bibliografía española, hay que destacar la monografía de A. Molina, Iglesia y Estado en el Siglo de Oro español. El pensamiento de Francisco Suárez (Universidad de Valencia, Valencia, 1977). Entre los estudios más recientes sobre el pensamiento político de Suárez, debe mencionarse a C. FARACO, Obbligo politico e libertà nel pensiero di Francisco Suárez (Franco Angeli, Milán, 2013).

4. B. ForTeZA, La influencia de Francisco Suárez sobre Thomas Hobbes, "Convivium” XI (1998) 40-79. 
de Suárez defendió acríticamente la validez de la potestad indirecta. En el momento en que desciende el volumen de los trabajos, la bibliografía española pierde el interés por una temática que, más allá de su utilidad para la teoría política contemporánea, es fundamental para comprender los primeros compases de la Modernidad5. Por este motivo, existe un relativo déficit de la bibliografía en castellano que este trabajo pretende subsanar.

En este artículo, en primer lugar, examinaré la postura de Suárez sobre la potestad indirecta. En segundo lugar, me detendré de modo más breve en la crítica de Hobbes. Por último, me preocuparé de mostrar en qué aspectos las doctrinas de estos dos filósofos pueden considerarse origen remoto de la solución que la contemporaneidad ofrece al problema de la doble legitimidad. Incluso si juzgo que la opción contemporánea no es ni la de Suárez ni la de Hobbes, explicaré por qué la hobbeseana se acerca más a nuestra comprensión.

\section{LA POTESTAD INDIRECTA COMO ATRIBUCIÓN FUNDAMENTAL DE UNA CIVIL POTESTAD CANÓNICA}

Las reflexiones de Suárez acerca de la potestad indirecta se concentran en el último periodo de su producción intelectual, cuando la preocupación por la filosofía política es dominante: De Legibus (1612) y Defensio fidei (1613). Tanto una causa interna como externa influyen en que Suárez dedique atención a su vena más política. Para justificar la redacción de De Legibus, el mismo Suárez recuerda el principio de que el teólogo no solo debe hacer conocer a Dios, sino también dirigir a los hombres a Él ${ }^{6}$. Por otra parte, Defensio fidei es una obra encargada tanto por la máxima autoridad de su país como

5. Es necesario señalar que la bibliografía anglófona sobre la filosofía política de F. Suárez ha sido muy abundante. Una revisión muy completa sobre el pensamiento político de los jesuitas, no exclusivamente españoles, puede encontrarse en $\mathrm{H}$. Höpfl, Fesuit Political Thought. The Society of Jesus and the State 1540-1640 (Cambridge University Press, Cambridge, 2004).

6. R. Scorraille, Francisco Suarez de la Compagnie de Fesus (Lethielleux, París, 1913) vol. II, 156. Hay traducción española, El P. Francisco Suárez de la Compañía de Jesús según sus cartas, sus demás escritos inéditos y crecido número de documentos nuevos (E. Subirana, Barcelona, 1917). 
por la de su religión. Antes de examinar su contenido filosófico, es necesario describir el agitado contexto político que rodea la aparición de Defensio fidei.

La publicación de esta obra puede entenderse como la culminación del proceso de separación y enfrentamiento entre los reyes de Inglaterra y la Iglesia católica cuyo inicio simbólico lo protagoniza la Supremacy Act (1534) dictada por Enrique VIII. La llegada al trono de Jacobo I continúa este conflicto al seguir reservándose el gobierno de la Iglesia de Inglaterra. Tras la Powder Plot, Jacobo exigirá a sus ciudadanos que juren que "el papa ni de su propia autoridad ni de otra alguna de la Iglesia [...] tiene algún derecho o potestad de deponer al rey". Pablo V encarga a Belarmino y Suárez que deslegitimen esta exigencia (Oath of Allegiance). Suárez tarda varios años en elaborar su tratado. Jacobo I esperaba ansiosamente la publicación de la Defensio, quizá porque suponía que la postura de Suárez iba a ser más acorde a sus intereses, parecida a la defendida por Barclay en De regno et regali potestate ${ }^{7}$. Cuando recibe en 1613 los extensos volúmenes en que se confirma y perfecciona la vieja doctrina de la potestad indirecta y de la legitimidad de la rebelión y la deposición del monarca por el papa, un enojado rey-filósofo Jacobo I ordena quemar el libro en Saint Paul Cross.

La potestad indirecta es un concepto central del pensamiento legal de Suárez. Para este pensador, la comunidad de cristianos se compone de dos sociedades — espiritual y terrenal-, con objetivos claramente diferenciados. El fin de la sociedad terrenal es natural; se limita a la paz y al bienestar. Por otra parte, el propósito de la sociedad espiritual es sobrenatural y consiste en evitar el pecado para salvar a los hombres. Al poder civil le corresponde lograr el primer objetivo; al papa, el segundo. Para alcanzar el fin natural, la sociedad no necesita la intervención de la Iglesia. Sin embargo, para conseguir el sobrenatural, la Iglesia requiere una colaboración negativa. Si la sociedad no busca adecuadamente el bien natural, puede conducir

7. La ansiedad de Jacobo I se detalla en la mayoría de los estudios biográficos. Cfr. R. Scorraille, op. cit., 189-190 y J. H. Fichter, Francis Suarez. Man of Spain (MacMillan, Nueva York, 1940) 293. 
a sus ciudadanos al pecado, impidiendo la misión del papa. Precisamente de esta asimetría en el modo de alcanzar los fines propios, aparece la posibilidad de que el papa intervenga en asuntos civiles.

En el pensamiento de Suárez, la potestad indirecta irrumpe en un contexto polémico. El estudio del contexto en Suárez es sumamente instructivo y contradice alguno de los principios del contextualismo de Cambridge. El contexto político no marca ni el contenido ni las fuentes de la Defensio Fidei ${ }^{8}$. Para determinar su postura acerca del poder político, Suárez polemizará principalmente con unos pensadores políticos papalistas ya irrelevantes en la primera década del siglo XVII. La potestad intermedia es reivindicada contra aquellos teólogos hierocráticos que afirman que el papa "posee un poder temporal directo [ habeat directam potestatem temporalem]" . Para esta corriente, el papa podría decidir de modo completo y directo sobre asuntos temporales. Si no lo hace, se debe a que prefiere delegar este poder en un rey. Tras la aparición de un Estado que no reconoce superior a comienzos del siglo XVI, el Suárez escritor político se desentiende de establecer una discusión directa con otro de los pensadores que marcan su época: Nicolás Maquiavelo y su concepción del poder político como realidad autónoma, en la que la esfera espiritual no tiene de jure precedencia alguna ${ }^{10}$. El escaso espacio consagrado a Barclay - lo que lo diferencia de un Belarmino, algo más inclinado a debatir con autores de su contexto intelectual directo- contrasta con la enorme cantidad de páginas de crítica a autores teocráticos de relevancia más bien secundaria a comienzos del XVII. Quizá el marco netamente eclesiástico de su filosofía política explica que su atención se centre en autores teocráticos que

8. Cfr. Q. SKInNer, Lenguaje, politica e historia (Editorial Universidad de Quilmes, Buenos Aires, 2007).

9. F. SuÁreZ, De Legibus (CSIC, Madrid, 1975) III, 6, 3, vol. V, p. 71.

10. A pesar de que la argumentación de Suárez no se mueve en el plano de reflexión política maquiaveliano, conoce y critica al secretario florentino. F. SUÁREZ, De Legibus, III, 12, 6, vol. V, p. 167: "No hay fundamento para el error de Maquiavelo. Hay que portarse mal para que el Estado vaya bien". Existe bibliografía sobre la relación entre Suárez y Maquiavelo: L. SIERRA, La moral política: el antimaquiavelismo en Suárez y Gracián, “Arbor” XLVIII (1961) 281-301. Puede recordarse que la perspectiva natural sobre el poder espiritual se materializará en el capítulo XI de El príncipe. 
habían sido lo suficientemente poderosos como para que en 1590 Belarmino y Vitoria fuesen incluidos en el Index por haber aceptado la potestad indirecta ${ }^{11}$.

El enfrentarse de modo tan claro a los teócratas ha contribuido también a que la teoría de la potestad indirecta suela ser considerada como intermedia ${ }^{12}$. Esta interpretación ha sido habitual también en lectores laicos. Quizá Bayle, si bien refiriéndose a Belarmino, sea el promotor más renombrado de esta lectura liberal:

Díganos, señor, piensa usted que algún jesuita, durante toda la vida de Sixto $\mathrm{V}$, confesaría que la lectura de los libros sobre $\mathrm{El}$ romano pontifice era un pecado mortal [...]? Este jesuita [Belarmino] tenía un temperamento que disgustó a la corte de Roma, sin placer a la de París. Es el destino habitual de los pareceres mitigados: no te consigue amigos y no pacifica a los enemigos y te deja en medio de dos facciones que se sitúan en los extremos opuestos $^{13}$.

Precisamente, en este trabajo criticaré esta interpretación moderada.

Es posible que en un plano puramente formal la postura de Suárez pueda dar pie a una lectura moderada, partidaria de una nítida distinción entre un poder plenamente dedicado a asuntos espirituales (Iglesia) y otro a terrenales (Estado). Cuando Suárez ataque a Fortunio García de Ercilla, distinguirá entre los fines del poder civil y del eclesiástico:

11. Ya en 1599 la teoría del poder directo aparecía como no ortodoxa, pues el partidario de la teocracia ALESSANDRO CARRIERO, De potestate romani pontificis adversus impios políticos (Padova, 1599) se incluyó en el Index.

12. A. Molina, op. cit., 253: "La potestad indirecta limita la omnímoda soberanía del Estado”. En la medida en que se considere la democracia una forma política moderada, también ilustra esta posición: J. H. FiCHTER, op. cit., 309: "Thus it was that the connecting link was broken between the great seventeenth century exposition of Catholic democracy and the acceptance of the Declaration of Independence in the following century".

13. P. BAYLE, Dictionaire historique et critique (París, 1820-1824,) vol. III, 279-280. B. Bourdin, op. cit., 137, ha insistido recientemente en que la teoría de la potestas indirecta es un "middle way". 
La razón es que la ley civil tiene como punto de mira la moralidad y el bienestar temporal de la convivencia humana [honestam utilitatem reipublicae bumanae] y, en cambio, la ley canónica atiende primariamente a la salvación del alma y a evitar los pecados [attendit saluti animae et ut peccata evitentur $]^{14}$.

La interpretación de Molina no es del todo transparente, pues su monografía recordará poco después que el significado de "espiritual" para Suárez se extiende por campos muy amplios:

Por cosas espirituales entiende nuestro autor aquellas cosas que por su naturaleza, su fin y los medios que emplea tienen una dimensión esencialmente sobrenatural. Aquí entran esencialmente todos los actos sobrenaturales, como los actos de virtud de la fe, los dogmas, los sacramentos, otras acciones sagradas ${ }^{15}$.

En este nivel de abstracción, parecería que Suárez percibe que la realidad está divida en dos tipos de objetos - los terrenales y los espirituales-, a los que les correspondería órdenes y poderes diferentes, dotados de atribuciones impermeables. Hasta aquí, todo confirma la interpretación liberal y moderada de su pensamiento.

Suárez favorecería la independencia de los poderes por otros motivos. El poder político parece contar con una existencia plena, independiente de la religión y de la moral. Por eso, Suárez concede a los paganos una aparentemente plena potestad política, ya que un rey no bautizado parece libre del poder de la Iglesia ${ }^{16}$. También confirmaría la autonomía de la política la defensa de que el rey conserva su poder de acuerdo a criterios de eficiencia política. Suárez tampoco reclamará la injerencia del papa sobre cuestiones temporales por puritanismo:

14. F. SuÁREZ, De Legibus, III, 11, 6, vol. V, 151.

15. A. Molina, op. cit., 225.

16. F. SuáreZ, Defensio Fidei (Instituto de Estudios Políticos, Madrid, 1970) III, 30, 4, vol. III, 369. 
Supongamos que aun siendo un malvado por otros conceptos, cumple el rey las exigencias de la honradez y la justicia a la hora de dictar leyes. En ese caso, en cuanto rey, es formalmente justo. La maldad de costumbres es entonces algo como accesorio y circunstancial que nada tiene que ver con el poder [Malitia autem illa se habet quasi concomitanter, et ideo non refert ad hanc potestatem ${ }^{17}$.

Por lo tanto, no justifica la intervención papal el estar gobernado por un príncipe políticamente efectivo, pero privadamente vicioso. La independencia de lo político parece salvada: un buen rey podría ir al infierno. El motivo de intervención papal no será la condena del príncipe, sino la del pueblo.

No hace falta llegar al examen de la noción de potestad indirecta para detectar actuaciones del poder eclesiástico fuera de su esfera. Contra esta tendencia, hay que recordar que el aspecto verdaderamente problemático de las relaciones entre los dos poderes surge en el pensamiento político de Suárez de las atribuciones civiles que, sin necesidad de recurrir al poder indirecto, le corresponden de suyo al eclesiástico ${ }^{18}$. La injerencia que puede representar la potestad indirecta debe entenderse como parte de la extensión civil que la potestad canónica alcanza en Suárez, aspecto en el que no ha insistido lo suficiente la bibliografía. La pregunta que debe volver a formularse es la siguiente: ¿cuál es la función de la autoridad eclesiástica en el pensamiento político de Suárez?

En primer lugar, llega a comunidades políticas ajenas a la autoridad espiritual del papa: los países paganos y herejes, como sin distinción Suárez considera a todas las variantes no católicas del cristianismo. El poder sobre este tipo de sociedades es muy diferente. En el caso de las paganas, la potestad papal goza de una sola atribución que ninguna autoridad civil puede eliminar. El papa puede obligar a permitir la propagación de la fe, "si los reyes paganos no

17. F. SuÁREZ, De Legibus, III, 10, 7, vol. V, 138.

18. Cfr. H. LaCerTe, The Nature of Canon Law according to Suárez (University of Ottawa Press, Ottawa, 1964). 
tienen súbditos cristianos, [...] la Iglesia no tiene poder sobre ellos, a no ser en el caso de que impidiesen la predicación del Evangelio"19. En el caso de las comunidades heréticas, las atribuciones son casi totales. Aunque de hecho no ejecute esta soberanía, el papa de jure puede intervenir del modo que le plazca sobre un poder civil hereje. No existe el reconocimiento de los países cristianos no católicos como una situación definitiva estable, sino como una injusticia que el mismo papa está encargado de revertir.

Comprobada la extensión del poder eclesiástico, es necesario examinar las atribuciones del que Suárez le dota. En la Defensio fidei, se recuerda que la potestad canónica decide de modo directo sobre todas aquellas cuestiones mixtas, sobre las que habitualmente se pronuncia tanto la autoridad civil como la eclesiástica. No hay duda sobre cómo deberán coordinarse. En caso de que una realidad sea dual - es decir, contenga en sí misma un aspecto espiritual y otro terrenal—, decidirá la potestad espiritual, sin necesidad de apelar a la potestad indirecta:

Pero algunas veces tiene algo de común con la materia de la ley canónica por razón del contenido sujeto a ambas leyes, por ejemplo, las leyes sobre los matrimonios, sobre los funerales, sobre los piadosos legados [legata pia]. [...] Pues bien, cuando las leyes civiles son de esta segunda clase, no solo indirecta, sino también directamente pueden ser enmendadas y anuladas por el poder espiritual, porque entonces la materia o es directamente espiritual o es del fuero mixto [misti fori], y por consiguiente el poder espiritual alcanza a ésta directamente ${ }^{20}$.

En este caso, lo dictado por el poder canónico borra absolutamente lo que de manera desviada haya podido dictaminar el poder civil, sin que sea necesario apelar a un grupo de súbditos que, por causa de una mala legislación, han incurrido en un comportamiento pecaminoso: "las leyes civiles permitían los matrimonios entre consanguí-

19. F. SuÁReZ, Defensio Fidei, III, 30, 6, vol. III, 370.

20. F. SuÁreZ, Defensio Fidei, III, 22, 11, vol. III, 330. 
neos en segundo grado: contra ellas prevalecen las leyes canónicas que las anulan"21.

Suárez da un paso más y concede al papa el derecho de legislar de modo exclusivo sobre un objeto ni espiritual ni mixto, sobre el que ni ha habido una mala legislación ni hay riesgo de que ésta se elabore:

Por último, las afirmaciones anteriores dejan entender la posibilidad eventual de que el papa delimite la materia canónica o la cuasi reserve — de suerte que sea exclusivamente canónica- no solo declarándola tal — como sin duda puede hacerlo cuando la materia misma es espiritual por su propia naturaleza y por decreto divino- , sino constituyéndola y eximiéndola y reservándola por razones espirituales, aunque por lo demás pudiera ser, de acuerdo a su naturaleza, materia de leyes civiles $^{22}$.

El bien de la Iglesia y la salvación de los hombres le permiten reservarse cualquier sección del ordenamiento legal. Quizá por parecerle excesivo, en su crítica, Hobbes pasará por alto este punto, el cual no solo un autor regalista puede interpretar como una extralimitación.

¿Qué ocurre en los países católicos? Si el poder canónico es poderoso en países herejes con el pretexto de restaurar la verdadera religión, en los países católicos, donde el credo verdadero se ha respetado, el poder canónico parecería privado de cualquier decisión sobre cuestiones civiles. Si la potestad indirecta actúa "para enmendar o derogar leyes civiles cuando pueden degenerar en ruina de las almas" 23 , solo de manera excepcional será necesaria esta corrección en los países donde el catolicismo sigue vigente. Por tanto, ahora el punto del máximo interés consiste en saber qué significa en concreto la salvación. ¿La práctica legislativa de los países católicos puede suponer un riesgo para la salud espiritual de modo frecuente o excepcional? Incluso si sugiere que se trata de una injerencia ex-

\section{Ibidem.}

22. F. SuÁREZ, De Legibus (CSIC, Madrid, 1981) IV, 11, 12, vol. VIII, 12.

23. F. SuÁreZ, De Legibus, III, 11, 6, vol. V, 151. 
traordinaria ${ }^{24}$, Suárez da dos respuestas: una más abstracta, centrada en la justicia de la ley. Otra, más concreta, la que define las materias sobre las que el papa puede intervenir gracias a la potestad indirecta.

La interpretación que Suárez da de la filosofía legal tomista parecería inclinarlo a considerar excepcional la posibilidad de una legislación tan injusta como para que el papa deba intervenir. Solo una ley injusta pone en riego la salvación de las almas. Para esta tradición a la que Suárez se suma, la ley injusta no es ley. De esta manera, el súbdito puede retirar la obediencia, incluso sin la autorización pontificia. Para evitar la anarquía — "toda vez que [las leyes] difícilmente pueden ser tan justas, que no puedan discutirlas algunos con aparentes razones"25_, Suárez limita las ocasiones en que el súbdito puede tener seguridad sobre la injusticia de la ley. ¿Cuándo el vasallo está autorizado a desobedecer? "Esta adecuación no consiste en otra cosa que en no mandar lo que la ley divina prohíbe, ni prohibir lo que ésta ordena. En este sentido es lo mismo estar en armonía con la religión que ser honesta" ${ }^{26}$. Solo en el caso de que un gobernante legislase literalmente contra la fe, se permitirá la desobediencia y se exigirá la mediación papal.

Aunque no es su objetivo, la cuestión del libro I de De Legibus donde se explica la justicia de la ley puede leerse como un límite para la intervención papal. Se trata de una restricción que el mismo Suárez no tendrá en cuenta, cuando, tanto en el mismo De Legibus como en Defensio fidei, describa las atribuciones que corresponden al poder indirecto. En ambos textos, se dice que el papa puede actuar como juez ("anular una sentencia injusta"), como árbitro entre dos soberanos ("avocar a sí una causa temporal [...] entre quienes no reconocen superior en lo temporal”) y como corrector de una legislación desviada. Suárez se detiene en el examen de esta responsabilidad. El papa podrá anular todas aquellas leyes que, aunque versen sobre una materia temporal, puedan ser ocasión de pecado. Desde un punto de vista político, el interés estriba en conocer qué leyes concretas

24. F. SuÁREZ, Defensio Fidei, III, 30, 8, vol. III, 370: "la administración indirecta tiene lugar raras veces y solo ocasionalmente".

25. F. SuáreZ, De Legibus (CSIC, Madrid, 1972) I, 9, 11, vol. II, 14.

26. F. SuÁrEZ, De Legibus, I, 9, 8, vol. II, 10. 
pueden poner en peligro el alma del súbdito, pues potencialmente hasta el más mínimo defecto legal podría conducir a que un vasallo se condenase. Lógicamente una ley que no prohíbe el consumo de alcohol podría constituir una ocasión de pecado en la medida en que permite la embriaguez. Suárez no detalla minuciosamente qué leyes particulares pueden dificultar la salvación, aunque, en ningún caso, se preocupará de restringir las posibilidades. En passant, menciona que el papa podrá desautorizar las leyes que permitan la prescripción de mala fe, que nieguen el alimento a los hijos naturales [filios spurios], ambos casos también mencionados en De Legibus. Añade también que el papa podrá derogar "las leyes que permiten la usura, el concubinato" 27 .

La pregunta que Suárez no responde es la más interesante: ¿existe algún contenido legal que el papa no puede interpretar como un perjuicio para la salvación? Si una ley sobre cualquier materia, sea del orden que sea, puede suponer una amenaza para la salvación, no existirá materia resguardada de la intervención pontificia. En este punto, es necesario hacer una distinción entre la lógica del argumento y la histórico-política.

Desde el punto de vista argumental, todo, absolutamente todo, puede suponer un riesgo para la salud espiritual. Como Molina interpreta, incluso el fomento de obras públicas podría autorizar la intervención papal a través de la potestad indirecta:

Es verdad que sobre muchas materias temporales: la construcción de un puente o de una carretera, el papa nunca legislará o avocará a su tribunal. Pero esto ocurrirá por razón de la no conexión de esa actividad, cosa o persona, al fin sobrenatural. Pero, si se diera dicha conexión el papa podría prohibir o promover la construcción de un puente, o de cualquier otra actividad política. Solo hará falta que ese puente fuera ocasión de pecado ${ }^{28}$.

27. F. SuÁREZ, Defensio Fidei, III, 22, 12, vol. III, 330.

28. A. Molina, op. cit., 226-227. C. Giacon, Suarez (La Scuola, Brescia, 1944) 97: "in quelle semplicemente temporali, come p. es., le leggi riguardanti la proprietà, l'autorità spirituale interviene soltanto indirettamente, cioè nel caso e in tanto in quanto fossero contra la morale e la religione". 
Propiamente, no existen realidades definitivamente temporales. Nada es tan absolutamente terrenal como para que en algún sentido no llegue a suponer un obstáculo para lo espiritual. Incluso si Suárez atribuyese a lo espiritual un contenido más restringido, cualquier objeto material — de acuerdo al ejemplo de Molina, la construcción de un puente - puede perjudicar a lo espiritual, quedando autorizada la intervención del poder canónico. Aunque la formulación puede sonar demasiado postmoderna, para Suárez, la realidad es reversible, perpetuamente interpretable. Nada de suyo es terrenal o espiritual. Si esta afirmación parece excesiva, es innegable que Suárez le reserva al papa, y no al soberano civil, la última decisión sobre qué es terrenal y qué espiritual ${ }^{29}$. Incluso si metafísicamente existen cosas puramente terrenales y realidades exclusivamente espirituales, políticamente la voluntad que distingue lo terrenal de lo espiritual es la pontificia. Suárez utiliza la metáfora del cuerpo y del alma para mostrar la jerarquía que existe entre estas dos instancias. Aunque tradicional, la metáfora no es del todo afortunada en la medida en que el alma carece de la potencia de convertir el cuerpo en su propia naturaleza espiritual, potestad de la que, en cambio, gozaría el poder papal.

Si la interpretación histórico-política fuese la misma que la lógica, realmente la potestad intermedia no se diferenciaría esencialmente de la teocracia, como Fabbri ha sugerido ${ }^{30}$. Se distinguirían exclusivamente en la manera de concebir el origen del poder: para los teócratas el origen del poder es sobrenatural, mientras que, para Suárez, existe un poder natural, en el sentido de que Dios no instaura el poder político de modo directo a través de su representante espiritual. Sin embargo, en la medida que interese más el ejercicio del poder que su origen, las diferencias no serían tan notorias. De acuerdo a las exigencias de la soberanía, la esencia del poder estriba

29. Ibidem, 252: "El papa es el único que puede decidir auténtica e inapelablmente cuándo una materia guarda o no relación con lo espiritual”. En el caso de Belarmino, la situación es idéntica. E. FABBRI, op. cit., 48: "Resta inteso che spetta al Papa valutare quando il proprio intervento è necessario".

30. Ibidem, 49: "Bellarmino pare quindi teorizzare, come gli ierocrati, un potere diretto ristretto a un uso eccezionale; tra le due teorie, molti interpreti hanno di fatto rilevato divergenze più apparenti che reali". 
en el quis iudicabit, en el quién decide. Más allá de que pueda haber aspectos temporales que se interpreten como espirituales por la causa final - la salvación o la condena-, el hecho de que sea el papa quien decida qué es material y qué espiritual lo convierte en el único soberano, al menos en los casos conflictivos. La diferencia entre el teócrata y Suárez será solo en que el poder político no es delegado. Pero el poder papal será soberano, pues nadie puede limitar ni reprochar sus interpretaciones. El papa de la potestad indirecta solo se diferencia del papa teócrata en que está algo más despreocupado de la política —no es conveniente que "le embarguen excesivas preocupaciones y afanes temporales" 31 - , pero cuando esta le interese, será el único juez.

El contexto histórico-político exige una interpretación menos literal. Por un lado, el rey Felipe III no vio en esta teoría un debilitamiento de su poder soberano y en ningún caso temió una intervención similar a la que el papado intentó ejercer. Y es fácil imaginar, en cambio, que alguna ley de la España de Felipe III pudiera poner en riesgo la salvación de los súbditos. La teoría de la potestad indirecta permite la intervención papal por cualquier ley que ponga en riesgo la salvación. De hecho, la reclama en un caso excepcional: el rey que se aleja de la fe. En el pensamiento de Suárez descansa un principio ajeno a la lógica estatal: no todo poder posible se hace efectivo. Por otro lado, otros pensadores muy cercanos a Suárez, como Mariana o Ribadeneyra, que escriben en castellano, jamás defenderán esta omnímoda potestad indirecta, sino que, al estilo de Barclay, optarán por una teoría de la independencia del poder civil y espiritual:

Confiesa Barclay que el Pontífice tenía la soberanía espiritual incluso sobre los reyes y emperadores y, sin embargo, negó la subordinación del poder temporal al espiritual y, en consecuencia, también negó que el Pontífice pueda introducir cambio alguno o disponer algo en las cosas temporales pertenecientes al derecho o al poder del rey ${ }^{32}$.

31. F. SuÁREZ, De Legibus, III, 6, 5, vol. V, 76.

32. Así se resumen la postura de Barclay en F. SuÁrEZ, Defensio Fidei, III, 21, 4, p. 321. 
A pesar del contexto polémico, esta obra debe entenderse más como una obra de eclesiología que de filosofía política. Eclesiológicamente, en un mundo ideal, la voz del papa es escuchada hasta por el soberano díscolo. Políticamente, esta postura se identifica con la de Barclay, salvo que el rey cometa el desatino de alejarse del catolicismo.

En cualquier caso, es legítimo que, como historiadores de la filosofía política, nos centramos en la lógica del texto, lo cual, además, parece haber sido la aproximación de Hobbes. Entonces se debe decir que, de ninguna manera, se puede considerar la teoría de la potestad indirecta como moderada en la articulación entre autoridad eclesiástica y civil por tres motivos. En primer lugar, permite que la autoridad eclesiástica se reserve aspectos de suyo materiales para legislar. En segundo lugar, se trata de una teoría esencialmente asimétrica: el poder eclesiástico puede corregir al civil cuando incumple su tarea, pero no el civil al religioso, porque este cumpliría siempre su misión propia. En tercer lugar, solo el papa decide qué es espiritual y qué material. Si quien juzga es soberano, el juicio de este monarca indirecto, si bien menos deseoso de actuar, es tan absoluto y tan definitivo como el del papa teócrata.

\section{LA INDISTINGUIBILIDAD ENTRE PODER PASTORAL Y PODER INDIRECTO}

Cuando en 1651 Hobbes publica en Leviatán su crítica del concepto de potestad indirecta - ausente tanto de De Cive como de Elementos-, nadie está ansioso por leer su obra. Posiblemente Felipe IV ni siquiera llegase a saber de ella. En 1651 España ha dejado de representar una amenaza para la soberanía inglesa, aunque el catolicismo de miembros de la familia real y la corte desestabilizase la política inglesa hasta 1688. A Inglaterra la amenaza en esta época una crisis interna de orden religioso, que acaba materiali-

Cfr. J. Mariana, La dignidad real y la educación del rey, ed. L. SÁnCheZ-Agesta (CEC, Madrid, 1981) 117, insistirá en que "separados netamente ambos poderes, se ha de procurar con ahínco que uno y otro estado estén unidos por lazos de estima y correspondencia mutua". 
zándose en una guerra civil. Aunque el Leviatán pretende acabar de una vez por todas con los conflictos civiles, Hobbes dedicará mucha atención a una doctrina eminentemente católica como la potestad indirecta, a pesar de su escasa participación en el inicio de la guerra. Nuevamente el contexto no determina el contenido del Leviatán de modo global y completo. Al igual que en el caso de Suárez, existe una cierta distancia entre el contexto histórico de la obra y el contenido del Leviatán. Ninguno de los combatientes en la guerra civil que Hobbes pretende acabar con su filosofía política era un defensor de la potestad indirecta. En ningún caso es la urgencia del contexto histórico, sino un íntimo desagrado, un profundo anticatolicismo lleva a Hobbes a desautorizar esta teoría central del pensamiento católico moderno.

En los párrafos finales de "Del poder eclesiástico" —el capítulo más largo del Leviatán —, Hobbes querrá deshacerse de la noción de potestad indirecta. En esta culminación del libro III "De un Estado cristiano", la potestad indirecta es rechazada por unos argumentos que no solo están implícitos a lo largo de todo el capítulo, sino que ya han sido expuestos el corpus del Leviatán. El lector que ha llegado hasta la última página del "Del poder eclesiástico" puede sentir que Hobbes se está repitiendo, cuando critica la potestad indirecta. Sin necesidad de entrar en el detalle de la crítica, a quien haya retenido el contenido de su filosofía política no le causará sorpresa que la potestad indirecta transgreda dos de los fundamentos políticos hobbeseanos. En primer lugar, desde un punto de vista natural, la potestad indirecta vulneraría la indivisibilidad de la soberanía y, por tanto, alentaría la guerra civil. En segundo lugar, desde la perspectiva sobrenatural, la potestad indirecta conferiría al papa unas atribuciones — de la corrección de ciertas leyes a la destitución de los reyesincompatibles con un poder canónico-pastoral carente de fuerza coactiva. Aunque Hobbes realizará un examen extraordinariamente detallado del texto de Belarmino - por su carácter representativo, ya que el cardenal actúa como el "campeón del papado frente a todos los demás príncipes" ${ }^{3}$ - , cualquier lector atento del Leviatán podría

33. T. Hobbes, Leviatán (Alianza, Madrid, 2001) XLII, 480. 
haber predicho que la potestad indirecta no va a recabar la más mínima aprobación en estas páginas finales.

Antes de reconstruir la crítica de Hobbes, es necesario apuntar que la especificidad de la teoría del poder indirecto desaparece de la crítica hobbeseana, lo que no resulta del todo sorprendente, sobre todo si se recuerda que, también para Suárez, la potestad indirecta se entendía como una atribución particular del poder canónico. Como coordinación entre el poder eclesiástico y el poder civil, la potestad indirecta era una parte de la capacidad de la potestad canónica de modelar la esfera civil. En el caso de Hobbes, el problema es similar. La potestad indirecta es criticada por pertenecer a una potestad espiritual que se extiende indebidamente por lo civil. Por este motivo, cuando Hobbes se deshaga de la potestad indirecta, no hará sino repetir la convicción de que el poder pastoral cristiano jamás podrá ser coactivo. Para Hobbes, el anuncio de Jesucristo "Mi reino no es de este mundo" es incompatible incluso con la posibilidad de influir en lo terrenal para conseguir los bienes espirituales. En tres pasos, Hobbes se deshará de la noción de potestad indirectapotestad espiritual. En primer lugar, rechazará la influencia civil del poder pastoral, tanto desde una perspectiva natural como sobrenatural. En segundo lugar, mostrará que el poder indirecto conduce al caos, al promover la existencia de dos poderes sobre una misma realidad. En tercer lugar, en la medida en que la potestad indirecta alienta a dudar de la soberanía, el Hobbes teólogo recordará que el verdadero mensaje del cristianismo es radicalmente incompatible con la desobediencia civil.

Para Hobbes, la noción de poder pastoral es absolutamente inválida. El único poder real se expresa a través mandatos coactivos cuya existencia depende del consentimiento de los individuos. Desde el punto de vista natural, el papa no puede ser soberano sobre naciones o individuos que no lo hayan aceptado como soberano: "ha de entenderse que [el papa] no aspira a ese dominio, como hacen otros soberanos, fundándose en la original sumisión de quienes van a ser gobernados"34. Esta teoría del origen popular del poder,

34. Ibidem, 472. 
incómoda para unos monarcas ingleses que juzgaban su soberanía entregada por Dios, desaparece en la traducción latina del Leviatán (1668). Repitiendo la tónica del tercer libro, Hobbes insiste en que las Escrituras invalidan la coactividad de un poder canónico, que no da leyes, sino consejos. Contra la extensión universal del poder papal, Hobbes ofrecerá dos argumentos teológicos. En primer lugar, no existe una comunidad universal de fieles: "hay varios cuerpos de cristianos, es decir, varias Iglesias" ${ }^{35}$. Más pertinentemente, recuerda que este poder no podría estar dotada de más atribuciones de las que Jesucristo confirió. ¿Qué atribuciones civiles habría transmitido a la potestad espiritual? Pocas páginas atrás se encuentra una respuesta contundente:

[...] el poder de excomunicación no puede extenderse más allá del fin para el cual los Apóstoles y pastores de la Iglesia han sido designados por nuestro Salvador; y ese fin no consiste en gobernar mediante órdenes y coacción, sino mediante la enseñanza y la dirección de los hombres en el camino que ha de conducirlos a la salvación en el mundo venidero ${ }^{36}$.

Solo la segunda venida de Cristo otorgará al poder pastoral la fuerza de la ley ${ }^{37}$.

Si elimina la coactividad del poder pastoral, tampoco le reconocerá una potestad indirecta. Sin dudar de su importancia tanto histórica como teórica — cuando afirma que "ésta es la doctrina que no solo Belarmino, sino también otros doctores enseñan en sus sermones y libros" ${ }^{38}$, es posible que recuerde a Suárez-, a Hobbes la teoría de la potestad indirecta le parece confusa. En la medida en que se trata de un mecanismo que puede permitir al papa intervenir en un amplio número de cuestiones legales y destituir al monarca de un país - Hobbes se concentra en este caso extremo-, la potestad indirecta supone una gravísima hasta pecaminosa extralimitación

35. Ibidem, 474.

36. Ibidem, 478 .

37. Ibidem, 474.

38. Ibidem, 472 . 
del poder pastoral. Además, le parece un mecanismo absolutamente arbitrario de intervención sobre la esfera civil: "[el papa] podrá deponer príncipes y Estados siempre que ello sea para la salvación de las almas, es decir, siempre que él quiera" 39 .

La teoría del poder indirecto disimula las ambiciones directas del poder pastoral: "Porque esa distinción entre poder temporal y espiritual es mera palabrería [is but words]" ${ }^{40}$. Por este motivo, la crítica a la potestad indirecta es idéntica de la que Hobbes dedicará a cualquier poder pastoral que quiera proclamar mandatos coactivos. Al ser la indivisibilidad de la soberanía uno de los pilares del pensamiento político de Hobbes, el poder indirecto confunde a los súbditos, quienes podrían pensar que realmente existe la posibilidad de respetar a dos poderes que legislan sobre un mismo asunto. Como es habitual a lo largo del Leviatán, volverá a repetir la máxima evangélica de que "Los hombres no pueden servir a dos señores", sin que le preocupe mucho que en el Nuevo Testamento la incompatibilidad no se da entre poder político y religioso, sino entre dinero y Dios (Mateo 6:24; Lucas 16:13). En el fondo, la aceptación de poder indirecto conduce a dos posibilidades nefastas para el poder civil: o a que alguien injustamente lo detente o a que los súbditos, al no saber a quién obedecer, comiencen una guerra civil.

Ninguna de estas dos consecuencias de la potestad indirecta puede agradar a rey alguno: "Creo que habrá pocos príncipes que no consideren esto injusto e inconveniente" ${ }^{41}$. En este punto del capítulo 42, Hobbes muestra su impaciencia con los reyes de los países católicos, los cuales habrían delegado tanto poder en el papa como para hacer innecesario el suyo. Curiosamente pocas páginas atrás, había reinterpretado con elegancia y sosiego las atribuciones de las el papa es responsable en las monarquías católicas:

Pues supongamos que un rey cristiano concede a otro la autoridad de ordenar pastores dentro de sus propios dominios, como

39. Ibidem, 472.

40. Ibidem, 473.

41. Ibidem, 473. 
varios reyes han hecho concediendo al papa ese poder. [...] Así, en los lugares donde un extranjero tiene autoridad para nombrar maestros, esa autoridad le ha sido dada por el soberano en cuyos dominios ese pastor enseña ${ }^{42}$.

En los pasajes finales de este capítulo 42, esta apolínea reinterpretación se transforma en ansiedad por la insensatez de unos reyes que aceptan la subsidiariedad sin ser ni siquiera conscientes. Irónicamente Hobbes les advierte de que, si aceptan tal debilitamiento de su poder, pierden automáticamente su condición regia:

pero desearía que todos decidiesen ser una de estas dos cosas: o reyes o súbditos [...]. Por tanto, deben aclararse [They ought therefore to ease them], o bien empunando las riendas del gobierno de un modo absoluto, o entregando esas riendas, también de modo absoluto, al papa ${ }^{43}$.

El endurecimiento del tono invita a pensar que estos pasajes finales fueron escritos después del grueso del capítulo, como si Hobbes hubiese sentido la necesidad de aclarar de una vez por todas que solo unos reyes insensatos pueden permitir las atribuciones papales sobre la esfera civil.

La crítica a la potestad indirecta se concluirá cuando Hobbes examine el acto más grave que esta herramienta permite: la destitución del rey. La teoría política de Hobbes permite interpretar la situación del rey desde dos puntos de vista: la destitución exitosa y la fracasada. Quien depone de modo exitoso es el verdadero soberano. Si los reyes católicos son depuestos por el papa $-\mathrm{y}$ Hobbes dará algunos ejemplos históricos en este capítulo-, entonces el verdadero soberano fue siempre el papa. Existe un segundo punto de vista: el de la deposición fallida. En este caso, el papa no es soberano, sino instigador de rebeldía. Estas páginas finales del Leviatán se limitarán a analizar este caso, el cual considera un pecado

42. Ibidem, 449.

43. Ibidem, 473. 
contra la obediencia que los cristianos deben a sus reyes, sean paganos o cristianos.

A lo largo del Leviatán, Hobbes repite que solo existe una creencia necesaria para salvarse: reconocer que Jesús es Cristo. Esta parquedad deontológica se reproduce en el plano de la moral cívica. Una vez instituido un poder político — cristiano o no-, el cristiano parece afectarle una sola obligación: la de obedecer. Por este motivo, la destitución de un rey, en la medida en que autoriza la desobediencia, supone la validación de un pecado. Si Belarmino dice que los apóstoles no depusieron a Nerón y al resto de los emperadores por falta de fuerza, Hobbes no acepta que aquella obediencia fuese mera cuestión de facto. Por un lado, Jesús pudo haber ejercido el poder temporal en vez de ser injustamente castigado; por otro, los Apóstoles aceptaron la obediencia a estos emperadores por "dictados de su conciencia"44. Carece de sentido, por tanto, no solo hablar de deponer, sino de desobedecer "a un rey infiel o hereje". Al deponer fracasadamente a un rey, el papa invita a los católicos a desoír su primera y casi única responsabilidad moral: la obediencia civil.

De esta manera, Hobbes rechaza la teoría de la potestad indirecta. A diferencia de Bayle y de tantos otros lectores católicos, no la considera una articulación moderada, sino una versión disimulada de una teoría que entrega la soberanía al papa. Gracias a este instrumento, la relación entre potestad civil y potestad canónico-pastoral se resuelve definitivamente a favor de esta última. Hobbes criticará a Belarmino, Suárez y cualquier otro partidario del poder indirecto por haber reducido lo civil a lo pastoral, lo que a la postre elimina la naturaleza cristiana de este poder. Si Suárez no estará de acuerdo con esta postilla, en la medida en que puede deponer, el papa será para Hobbes el verdadero soberano.

Si la teoría del poder indirecto se entendía en Suárez como una manera de coordinar esferas, de corregir lo civil cuando impide alcanzar lo espiritual, en estos pasajes finales del capítulo 42 Hobbes no expone ningún mecanismo de coordinación. Existe, sin embargo, indicios también aquí de cuál es la mejor manera de conciliarlas.

44. Ibidem, 477. 
Su insistencia en que el poder pastoral es meramente espiritual, su falta de coactividad, le impide aceptar que lo espiritual imponga mandatos coactivos sobre ningún aspecto. Tanto desde un punto de vista sobrenatural como natural explica por qué el soberano puede mandar sobre lo religioso. En primer lugar, sobrenaturalmente, el soberano aparece como intérprete de los mandatos espirituales: "Ambos tipos de funcionarios dependen del soberano civil, el cual debe, ciertamente, hacer que sus mandatos civiles estén dirigidos a la salvación de las almas, pero que no está sujeto a nadie sino a Dios"45. Desde el punto de vista natural, el soberano tiene derecho a controlar las opiniones que se expresan en la sociedad como exigencia fundamental. Hobbes es un pensador barroco, impregnado de un ambiente cultural contrarreformista. La paz social, principal deber del soberano, solo se puede conseguir, si se posee el control de las opiniones que circulan por la sociedad:

En sexto lugar, va anejo a la soberanía el ser juez de qué opiniones y doctrinas desvían de la paz, y de cuáles son las que conducen a ella [...]. Pues las acciones de los hombres proceden de sus opiniones y en buen gobierno de las opiniones radica el buen gobierno de los actos de los hombres para la consecución de la paz y la concordia. Y aunque en materia de doctrina no hay que fijarse en otra cosa que no sea su verdad, no repugna hacer de la paz el criterio para descubrir lo que es verdadero ${ }^{46}$.

\section{LA INCLINACIÓN A LA MONOCRACIA}

Frente a la solución contemporánea que acepta la independencia del poder religioso y del político en sus respectivos ámbitos, tanto Suárez como Hobbes ofrecen posturas contrastantes con este acuerdo. Ambos intentan encontrar una conciliación desde el cristianismo más que desde el Estado neutral que respeta las creencias religiosas de los ciudadanos. Su cristianismo confía en una comunidad entre

45. Ibidem, 475.

46. Ibidem, XVIII, 162-163. 
fe y razón. En ningún momento consideran ni al cristianismo ni a la política una fuente irremediable de conflictos, sino que solo las malas interpretaciones conducirán o bien a una guerra civil larvada (Hobbes) o a un deterioro del cristianismo (Suárez). Por equivocación, la religión cristiana suscita de facto conflictos. El acuerdo llega más lejos. Ambos piensan que la conciliación solo es posible, si uno de los poderes se subordina al otro. Si el Estado debe subordinarse a la Iglesia para Suárez y la Iglesia al Estado para Hobbes, la posibilidad del conflicto solo desparecerá cuando se reconozca la unidad de la soberanía.

Si es un hecho histórico que el conflicto entre lo político y lo religioso se ha controlado también en un contexto institucional que reconoce diversidad de jurisdicciones, hay que examinar la lógica que valida la monocracia, pues en principio no admite el acontecimiento histórico que se acaba de señalar. Para Suárez, el papa es un soberano, más que indirecto, poco frecuente: el reino de Dios solo le obliga a actuar por una causa: la unidad de la fe. Incluso si puede gozar de numerosos motivos para intervenir sobre la esfera civil, solo la unidad del catolicismo le llevará a intervenir. De manera unilateral el papa decretará cuándo la unidad católica está en riesgo y cuándo por tanto debe corregir lo civil. La inteligencia de un sujeto, y no la conflictividad objetiva de una tesitura, determinará la acción. En suma, el papa puede liberar de la obediencia a los súbditos católicos de Isabel, para menos de un siglo después criticar el excesivo procatolicismo de Jacobo II. Al fin y al cabo, el motivo de la decisión política es más religioso que político, más pontificio que católico, más subjetivo que objetivo.

Al contrario, en Hobbes el criterio es político. ¿Por qué el soberano debe decidir cómo se vive la fe de modo comunitario? Porque la vida política lo exige: no puede haber paz social sin este control intelectual. De hecho, el soberano hobbeseano puede delegar a una institución externa la organización religiosa sin perder por ello la soberanía, así como el papa, para Suárez, podía favorecer a un poder civil con la misión de restaurar la cristiandad sin perder el poder soberano. Si el soberano hobesseano necesita control de religión, se debe a que prevé que la religión descontrolada conducirá 
a la guerra civil. Fácticamente la previsión de Hobbes no se cumple. La paz social no exige una unidad tan estricta. Hobbes tiene una visión excesivamente lógica de la subjetividad religiosa: puede haber épocas en que varias religiones, con nociones de castigo y de obediencia diferentes de las que proclama el Estado, pueden ser perfectamente respetuosas con un conjunto legislativo, que si, en foro interno les desagrada, en el externo es cuidadosamente respetado.

Ambos autores quedan alejados de la contemporaneidad. Si con Hobbes estamos de acuerdo en el principio, su previsión es desacertada, marcada por la memoria reciente de una guerra civil de origen religioso. En el caso de Suárez, se trata de un paradigma inconmensurable con el nuestro, en la medida en que la restauración de una única fe ya no se puede entender como criterio político. Si de Suárez nos aleja el paradigma, de Hobbes tan solo nos distancia la magnitud de atribuciones religiosas que conserva el poder, incluso si la autoridad civil sigue conservando la decisión última. Ella decide qué es religioso y qué político, solo que de manera menos invasiva que la reclamada por Hobbes ${ }^{47}$.

47. Este trabajo ha sido financiado por el Fondecyt 11140310 del Gobierno de Chile y el proyecto de investigación HAR 2013-45788-C4-3-P dirigido por Francisco José Aranda López. 
